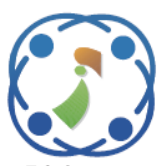

\title{
MIMO Fuzzy to Improve Search Speed and Reduce Oscillation in Maximum Efficiency Point Tracking of Small-Scale Compressed Air Energy Storage
}

\author{
Andi Setiawan ${ }^{1,2 *}$ \\ Hajime Miyauchi ${ }^{3}$ \\ Maurdhi Hery Purnomo ${ }^{1,4,5}$ \\ Ardyono Priyadi ${ }^{1}$ \\ ${ }^{l}$ Departement of Electrical Engineering, Institut Teknologi Sepuluh Nopember, Indonesia \\ ${ }^{2}$ Departement of Electrical Engineering, Universitas Jember, Indonesia \\ ${ }^{3}$ Department of Computer Science and Electrical Engineering, Kumamoto University, Japan \\ ${ }^{4}$ Departement of Computer Engineering, Institut Teknologi Sepuluh Nopember, Indonesia \\ ${ }^{5}$ University Center of Excellence on Artificial Intelligence for Healtcare and Sociaety (UCE AIHeS), Indonesia \\ * Corresponding author's Email: andi.setiawan14@mhs.ee.its.ac.id
}

\begin{abstract}
This paper presents the research results on a small scale compressed air energy storage (SS-CAES) operated at its maximum efficiency value in the discharged phase. This study used two methods to find the maximum efficiency; Standard Perturb and Observe (Standard P\&O), and Multiple Input Multiple Output Fuzzy Perturb and Observe (MIMO Fuzzy P\&O). The essential ideas of this study are to operate SS-CAES in its maximum efficiency in specific loading power and to improve the performance of standard $\mathrm{P} \& \mathrm{O}$ method in achieving maximum efficiency and reduce the oscillation amplitude of the efficiency value as well. To do this, in this study, we use two devices, namely a motorized valve to ensure sufficient power required for the load and a boost converter whose duty cycle will be adjusted so that the system can operate at its maximum efficiency. The study was conducted using a simulation model and compared these two methods performance for the same loading case. The experimental results reveal that the addition of the MIMO Fuzzy algorithm can improve the performance of the Standard P\&O method in accelerating maximum efficiency achievement and reducing oscillations when the system has reached the maximum operating points. The performance improvement on the maximum efficiency point tracking (MEPT) in SS-CAES operations, evidenced by the increase in the average efficiency value in the given loading scenario of about $1.22 \%$. Besides, the application of MIMO Fuzzy P\&O also impacts reducing the amplitude of speed oscillations in the steady-state area, which is about half of the amplitude of speed oscillations that occur with the application of the standard P\&O method. This proposed method also shows better performance than the MEPT method used in previous studies in terms of accelerating maximum efficiency achievement.
\end{abstract}

Keywords: MIMO fuzzy, Energy storage, Small-scale CAES, P\&O, MEPT.

\section{Introduction}

The application of energy storage systems using compressed air or compressed air energy storage (CAES) for large-scale electricity has become an attractive option if it is technically possible to apply [1-5]. This attractiveness is indicated by the operation of several large-scale CAES facilities in various countries such as Morocco with an installed capacity of $400 \mathrm{MW}$, in Korea and Israel each with a capacity of $300 \mathrm{MW}$, in Germany with a capacity of $290 \mathrm{MW}$ and the smallest in America with a capacity of 110 MW [2-4]. Studies to improve large-scale CAES systems' performance are also continuously developed to find the optimal operating strategy that makes this energy storage system even more attractive to become a large-scale energy storage system [6-9].

With the successful implementation of largescale CAES it finally brought inspiration to some researchers to create a CAES technology with a smaller size or commonly known as Small Scale Compressed Air Energy Storage (SS-CAES). This 
technology is an alternative system to overcome problems of energy storage, especially in terms of land requirements (geological formation), compactness, and portability [10,11]. Furthermore, several applications from SS-CAES have been widely developed to support the integration of energy storage with renewable energy $[5,12,13]$.

In CAES-related research, both large and small scales, several development topics have been published including thermodynamic issues [2,14,15], modeling [16-18], economic analysis [19,20], and the most popular issue is system optimization in the discharged phase [10,18,21-23].

Several attempts were made to improve process efficiency in this discharged phase, either by combining SS-CAES with other energy storage media to develop soft computing methods to operate more optimally [10,18,21-27].

One of the exciting studies is a research conducted to develop Maximum Power Point Tracking (MPPT) by V. Kokaew et al. [27]. It controls the Duty Cycle (DC) of a Buck converter to push and suppress the rotational force of air motor so that its air consumption can follow load changes and generate power following the MPPT line. The results obtained indicate that the system with this setting can reach the expected maximum power points. A paper has also been disseminated by V. Kokaew, which specifically discusses the operation of SS-CAES at its point of maximum efficiency (MEPT) [25].

In both studies, the search algorithm for optimum conditions, namely maximum efficiency point tracking and maximum power point tracking, was performed using Perturb and Observe (P\&O) methods [28-31]. However, using a combination of the buck converter and the $\mathrm{P} \& \mathrm{O}$ algorithm, the turbine speed (in this case, the air motor) must be high enough so that the generator can produce a high enough voltage to make the buck converter having an acceptable range of voltage values. The $\mathrm{P} \& \mathrm{O}$ algorithm then adjusted this voltage to a particular value, so the system as a whole can operate at the point of maximum power or maximum efficiency. Those two studies also did not determine the value of the output voltage of the converter. In other words, the value of the voltage can be anything as long as the system can transfer its maximum power to the load or the operating system with maximum efficiency under any conditions of air pressure in the storage tank.

This study adds another condition to the MEPT algorithm. The voltage applied to the existing resistive load must be at about 12 volts. For this reason, in this study, two control devices are used. They are a motorized valve to ensure the sufficient power and a boost converter placed at the generator output to adjust the system to operate at its maximum efficiency.

The reason for choosing the boost converter in this study is that hopefully, this system can search maximum efficiency at a reasonably low generator speed and still guarantee that it can provide sufficient power to the load. A voltage of about 12 volts, which is the load's nominal voltage, indicates the adequacy of power is at this load.

Furthermore, to increase the speed of the Standard $\mathrm{P} \& \mathrm{O}$ method in finding the maximum efficiency operating point and reducing oscillations at the maximum efficiency point, a MIMO Fuzzy controller is added, which will determine the delta duty cycle (DDC) value and starting duty cycle of the pulse width modulation (PWM) signal from the boost converter. This research is a simulation-based study. The component and subsystem models are built based on the manufacturer's information and the calculation of system components that must be built as needed.

We arrange the discussion in this paper into several sections as follows. Section 2 discusses the modeling of the components involved in building this SS-CAES. In Section 3 described the P\&O Standard method and the problems that will be solved with the proposed methods. Section 4 explains how a Fuzzy MIMO is added to the standard $\mathrm{P} \& \mathrm{O}$ algorithm to improve its performance. Furthermore, section 5 discusses the experimental results, which show that this proposed method has successfully corrected the MEPT method's weaknesses with standard P\&O. Finally, in the conclusions section, we summarize the results of this study.

\section{System modelling}

To simulate this system, we first need to implement the system components into models. This section describes how we develop a model of the components involved in the small-scale air energy storage system developed in this study.

Fig. 1 shows the SS-CAES configuration, which will be modeled and analyzed. The system divided into a pneumatic part consisting of a storage tank or



Figure 1. System configuration of SS-CAES 
air tank (ST), air motor (AM), and control components such as pressure sensors $\left(p_{T}\right.$ and $p_{i}$ ), airflow sensors (AF), and linear motorized valves (M) which control the incoming air pressure to AM. The next part is the permanent magnet direct current generator (PMDC), where the shaft is coupled directly to the air motor, which functions as a turbine so that the speed of PMDC $\left(\omega_{r}\right)$ is also the speed of AM.

The generator's output terminal is connected to the third part of the system, where a controllable $\mathrm{dc} / \mathrm{dc}$ boost converter is placed to supply power to a variable resistive load.

The final part of the system is a controller which receives all sensing signals and generates control signals for the $\mathrm{dc} / \mathrm{dc}$ boost converter and motorized valve. The motorized valve signal is a control signal to ensure the system provides sufficient power for the specified resistive load to operate at a nominal voltage of 12 volts. Another control signal given to the $\mathrm{dc} / \mathrm{dc}$ boost converter is to provide the appropriate DC for the system to operate in its area of maximum efficiency.

All these parts or systems are modeled and simulated using Matlab ${ }^{\mathrm{TM}}$ based on the characteristics and parameters informed by the manufacturer and the characteristic data obtained from experiments.

\subsection{Air tank model}

If dry air is assumed to contain about $80 \%$ Nitrogen $\left(N_{2}\right)$, a diatomic gas, the relationships between temperature, volume, and pressure are given in Eq. (1):

$$
p_{T} V=m R T
$$

Where $R$ is the specific constant of gas in $\mathrm{J} /(\mathrm{kg} . \mathrm{K})$, and $V, p_{T}, m$, and $T$ are respectively, the volume occupied by the gas measured in $\mathrm{m}^{3}$, the pressure of the gas in Pascal, the mass of the gas in $\mathrm{kg}$ and the temperature of the gas in Kelvin.

Air mass flowing out of the tank can be derived from Eq. (1) as:

$$
\dot{m}=\frac{V}{R T} \frac{d p}{d t}
$$

In this simulation, air mass flow $\dot{m}$ obtained from the volume flow as the air tank model's output, multiplied by a constant $\rho$, which is the density of air.

The integration of this mass flow rate $\dot{m}$ enables calculations of the air mass flowing out of the storage tank and the pressure drop of air in the storage tank, as shown in Eqs. (3) and (4).

$$
\begin{gathered}
m_{s}(t)=m(0)-\int \dot{m} d t \\
p_{T}(t)=\frac{R T}{V} m_{s}(t)
\end{gathered}
$$

\subsection{Air motor model}

In this work, the air motor LZB 14 AR034 $(100 \mathrm{~W})$ is used [24]. The air motor's mechanical power $\left(P_{m}\right)$ equation as a function of air motor speed $\left(N_{r}\right)$ in inlet pressure $\left(p_{i}\right)$ changes as follows:

$$
P_{m}=\frac{\pi}{30} T_{o}\left(p_{i}\right)\left[N_{r}-\frac{N_{r}^{2}}{N_{o}\left(p_{i}\right)}\right]
$$

In Eq. (5), $N_{o}\left(p_{i}\right)$ is the free rotate speed, and $T_{o}\left(p_{i}\right)$ is the stall torque in each $p_{i}$ value.

Another essential characteristic of the air motor to model is the volume flow $\left(\dot{V}_{a}\right)$ which can be expressed as:

$$
\dot{V}_{a}=\dot{V}_{\max }\left[c_{a 1}-c_{a 2} e^{\left[\frac{N_{r}-c_{1}}{c_{2}}\right]^{2}}\right]
$$

Where $\dot{V}_{\text {max }}$ is the maximum volume of airflow, and $c_{1}, c_{2}$, and $c_{3}$ are constants obtained from the curve fitting process. Fig. 2 shows the plot of mechanical power $\left(P_{m}\right)$ and the volume of airflow $\left(\dot{V}_{a}\right)$ of the LZB 14 AR034-111 [32].

At isentropic condition, the input power to the air motor can be calculated as in:

$$
P_{a m}=\frac{\gamma}{\gamma-1} p_{a} \dot{V}\left[\left(\frac{p_{i}}{p_{a}}\right)^{\frac{\gamma-1}{1}}-1\right]
$$

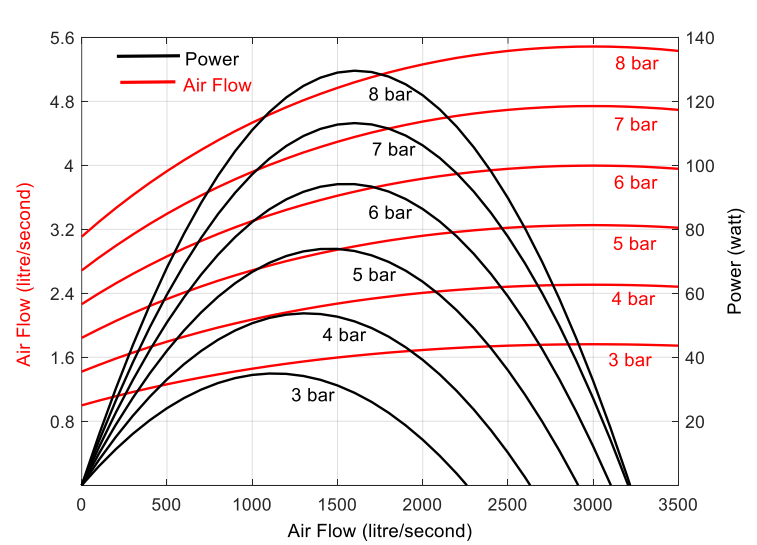

Figure. 2 Power and air flow diagram of air motor 


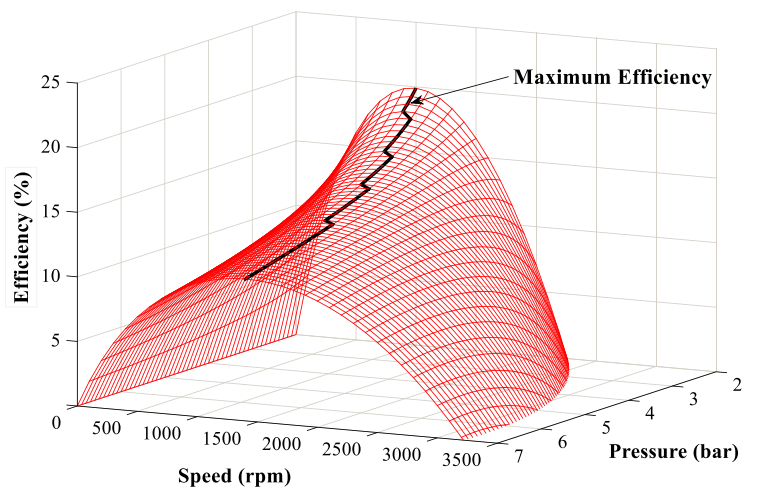

Figure. 3 Efficiency of LZB-14-AR034-11

Where $p_{a}$ is the air pressure at the outlet of air motor and $\gamma$ is isentropic constant.

The efficiency of the air motor is calculated as:

$$
\eta_{a m}=\frac{P_{m}}{P_{a m}} \times 100 \%
$$

Fig. 3 shows the efficiency and maximum efficiency line of the air motor LZB-14-AR034-11 calculated using this air motor's informed characteristic.

\subsection{PMDC generator model}

The permanent magnet direct current generator (PMDC) combined with a boost converter model is shown in Fig. 4. Newton's 2nd law obtains the dynamic equation of PMDC generator driven by a prime mover (air motor), as

$$
T_{m}=T_{e g}+B_{t} \omega_{r}+J_{t} \frac{d \omega_{r}}{d t}
$$

Where $\omega_{r}$ is the angular velocity of the air motor and the generator as well, $K_{-} e$ is the generator's torque constant, $B_{-} t$ is the total of the viscous friction coefficients of the combined air motor and generator, and $J_{t}$ is the combined moment inertia of the air motor and the generator. Consequently, the shaft of the air motor given by:

$$
P_{m}=T_{m} \omega_{r}
$$

The back emf of the generator, $E_{a g}$ is given by:

$$
E_{a g}=K_{m} \omega_{r}
$$

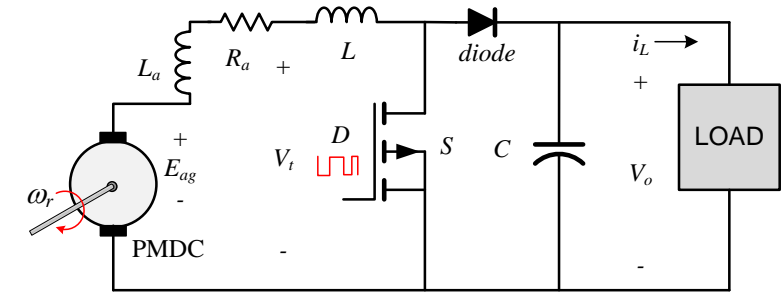

Figure. 4 PMDC and boost converter circuit model

Table 1. Specifications of generator

\begin{tabular}{cll}
\hline Symbol & \multicolumn{1}{c}{ Description } & \multicolumn{1}{c}{ Value } \\
\hline \hline$R_{a g}$ & Armature resistance & $0.43 \Omega$ \\
$L_{a g}$ & Arnature inductance & $0.9 \mathrm{mH}$ \\
$K_{e}, K_{m}$ & Torque and speed constant & $0.08 \mathrm{~N} . \mathrm{m} / \mathrm{A}$ \\
$J_{t}$ & Total of moment enertia & $2.119 \times 10^{-4} \mathrm{~kg} / \mathrm{m}^{2}$ \\
$B_{t}$ & Viscous friction coefficient & $2.094 \times 10^{-6} \mathrm{~N} . \mathrm{m} . \mathrm{s}$ \\
$C$ & $\begin{array}{l}\text { Capacitance of boost } \\
\text { converter }\end{array}$ & $0.0051 \mathrm{~F}$ \\
$L$ & $\begin{array}{l}\text { Inductance of boost } \\
\text { converter }\end{array}$ & $2.133 \times 10^{-4} \mathrm{H}$ \\
\hline
\end{tabular}

Where $K_{m}$ is the speed constant of the generator.

The load torque of coupling shaft is generator's electromagnetic torque, i.e.,

$$
T_{e g}=K_{e} i_{a g}
$$

Where $K_{e}$ is the torque constant and $i_{a g}$ is the armature current of the generator.

Finally, the terminal voltage generated by the generator can be determined using Eq. (7).

$$
V_{t}=E_{a g}-R_{a g} i_{a g}-L_{a g} \frac{d i_{a g}}{d t}
$$

The average output of voltage $V_{o}$ of the boost converter depends on the duty cycle $(D C)$ of the MOSFET,

$$
D C=1-\frac{\eta_{C} V_{t}}{V_{o}}
$$

where $\eta_{C}$ is the efficiency of boost converter.

The parameters of the PMDC generator for the PMDC model shown in Table 1. These parameters based on the manufacturer's information of MOOG C-34-L60-10 brushed permanent magnet direct current motor [33].

\subsection{Motorized valve model}

A motorized valve is a pressure regulator valve driven by a servo direct current motor. The opening of this valve is the integration of all outlets generated 


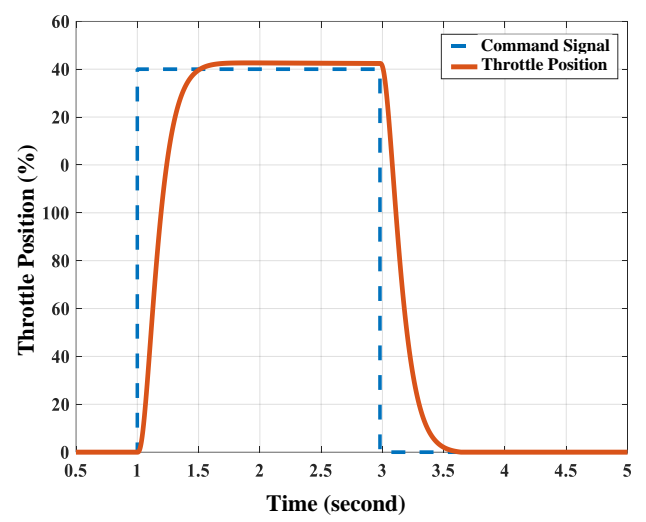

Figure. 5 Valve response

by the servo motor rotation. The model of this valve can be expressed as a motor transfer function as express in Eq. (15). With the inertia value, the inertia of the motor and valve is the equivalent inertia, as expressed in Eq. (16) [28].

$$
\begin{gathered}
\frac{\omega_{s}(s)}{E_{a}(s)}=\frac{K_{i s}}{s^{2} J_{e q} L_{a s}+s J_{e q} R_{a s}+K_{i s} K_{b s}} \\
J_{e q}=J_{1}+K_{g}^{2} J_{m}
\end{gathered}
$$

$K_{g}$ is the gear ratio of motor servo. $J_{1}$ and $J_{m}$ are valve inertia and motor inertia respectively.

Furthermore, a comparison of the input pressure and output of the valve is the ratio or percentage of the actual opening to the valve's total openings.

\section{Standard MEPT method}

The SS-CAES system's operation is based on two conditions; the adequacy of the power required by the load and the operating point that produces the best efficiency. Because the load on this system is a resistive load, to ensure the adequacy of power at that load is by making the output voltage on the $\mathrm{dc} / \mathrm{dc}$ converter about 12 volts, the nominal operating voltage of the load. Furthermore, to make this system operates at maximum efficiency, the duty cycle (DC) of the $\mathrm{dc} / \mathrm{dc}$ boost converter will be tuned so that the combination of the turbine's efficiency, generator, and $\mathrm{dc} / \mathrm{dc}$ boost converter reaches its best value.

A perturb and observe or $\mathrm{P} \& \mathrm{O}$ algorithm is applied to always look for a better efficiency value until the best efficiency value is obtained [28, 31, 34, 35]. Fig. 6 shows a flow chart explaining how this method of finding the maximum efficiency value works.

This standard $\mathrm{P} \& \mathrm{O}$ method works to control two



Figure. 6 Standard MEPT search algorithm

devices; a motorized valve which functions to ensure the adequacy of the required load by maintaining the load voltage $\left(V_{\mathrm{o}}\right)$ of 12 volts, and a dc/dc boost converter that works by varying the DC value so that the turbine-generator can operate with higher efficiency and finally reach the maximum efficiency value. The total efficiency (Eff) of the system, namely the ratio of load power and air motor input power and generator speed $\left(\omega_{\mathrm{r}}\right)$, will be used as information to guide control with this $\mathrm{P} \& \mathrm{O}$ algorithm.

We divided the CAES operation into three periods; transient period, tracking period or search, and the period where the system reaches its best efficiency or steady-state period.

When a transient condition occurs, due to the addition or release of the load, to ensure the system immediately works at its nominal voltage, which is about 12 volts, a PI controller works to regulate the motorized valve's opening. [36-39].

After the Transient period is over, a tracking or searching period begins, where the $\mathrm{P} \& \mathrm{O}$ algorithm adjusts the DC value of the $\mathrm{dc} / \mathrm{dc}$ boost converter to achieve maximum efficiency. This tracking period runs continuously.

The main problem with this standard $\mathrm{P} \& \mathrm{O}$ method is the oscillations that occur when the system reaches the expected optimal conditions. The oscillation amplitude magnitude depends on the magnitude of the change in the applied DC value (delta duty cycle). The greater the value of the delta duty cycle (DDC), the greater the oscillation in the steady-state area. Conversely, if a small DC value is applied, although this will reduce the number of oscillations in the steady-state region, it can slow the process to achieve maximum efficiency points [32]. 


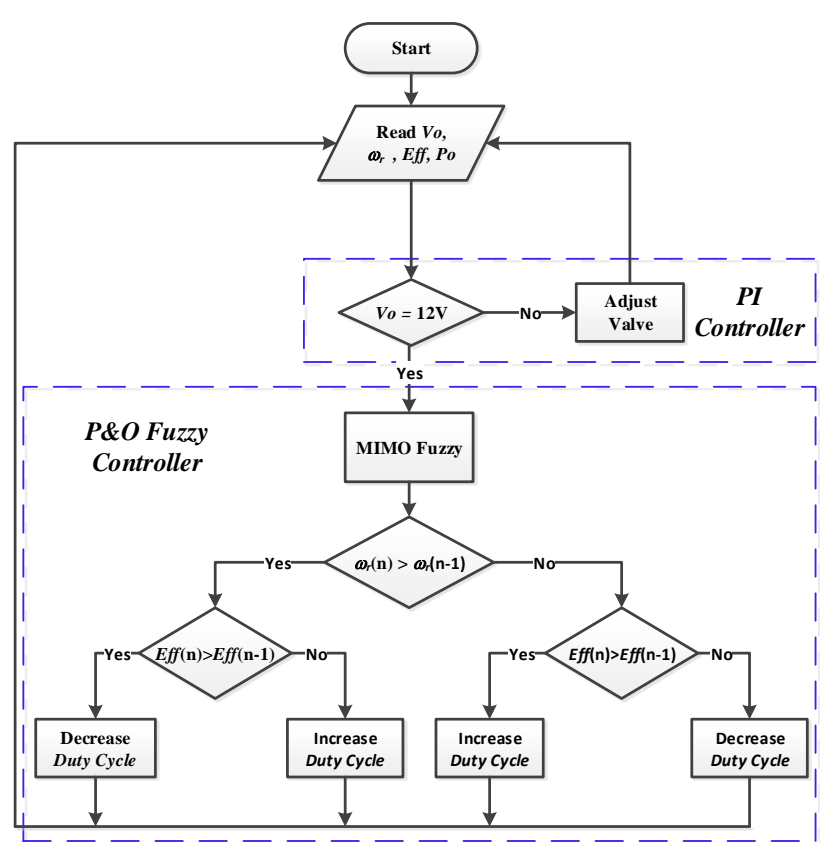

Figure. 7 Proposed MEPT search algorithm
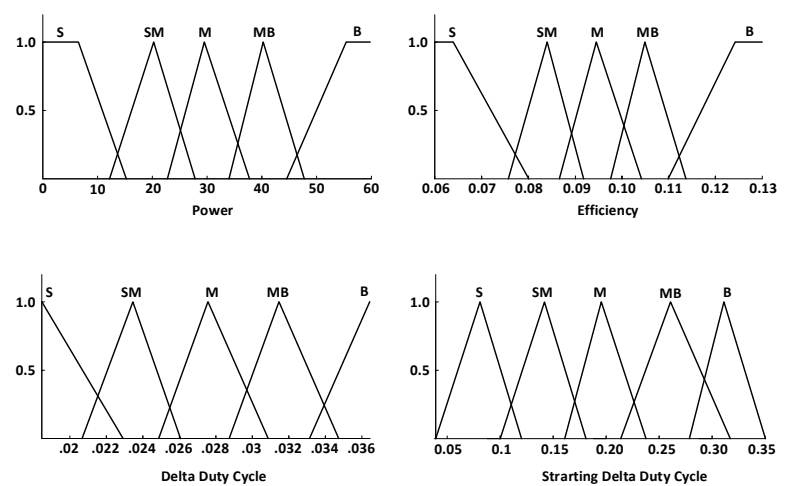

Figure. 8 MIMO fuzzy membership functions

\section{Proposed MEPT method}

The MEPT method proposed in this study adds multiple inputs and multiple outputs fuzzy (MIMO Fuzzy) to determine the DDC and starting duty cycle (SDC) used in the search period [40-43].

DDC adjustment aims to reduce the oscillation amplitude in the steady-state period, while SDC determination aims to accelerate the search for maximum efficiency operating points. Fig. 7 shows the algorithm of MIMO fuzzy P\&O.

The fuzzy controller reads the efficiency (Eff) and output power $\left(P_{o}\right)$ values at each $\mathrm{P} \& \mathrm{O}$ step and sets the SDC and DDC values based on the MIMO fuzzy membership function and the rule base. Fig. 8 and Fig. 9 show the membership function and rule base for the MIMO fuzzy controller applied to this system.

The grouping of output power values and efficiency values in input membership sets is determined based on an investigation of the previous standard M\&O method results. Determining the

\begin{tabular}{|c|c|c|c|c|c|}
\hline Power & $S$ & SM & $\mathbf{M}$ & MB & B \\
\hline$S$ & & & & & \\
\hline SM & & & & & \\
\hline M & & & & & \\
\hline MB & & & & & \\
\hline B & & & & & \\
\hline
\end{tabular}

Figure. 9 MIMO fuzzy rule base

membership sets of SDC and DDC values and the rule base is also done by investigating the output of standard P\&O MEPT.

In Fig. 8, the membership function of the inputs and the outputs, and in Fig. 9, the rule base, the letter $\mathrm{S}$ means small, $\mathrm{M}$ means medium, and $\mathrm{B}$ means big. For example, SM means power, efficiency, SDC, and DDC values with small-medium values, while MB means membership with medium-big values.

\section{Results and discussion}

We tested the $\mathrm{P} \& \mathrm{O}$ performance equipped with MIMO fuzzy proposed in this study using a loading scenario previously used to test the same CAES system's performance with a standard $\mathrm{P} \& \mathrm{O}$ method. The load used is a resistive load with values, as in Table 2.

\subsection{Performance of the MEPT}

Fig. 10 shows the performance of the proposed method against the performance of standard $\mathrm{P} \& \mathrm{O}$. At each loading period, it appears that the proposed method can reach the maximum efficiency value faster than the standard P\&O method. This acceleration is the effect of applying the starting duty cycle value (SDC) as one of MIMO Fuzzy's outputs.

This method can also reduce the oscillation amplitude from the efficiency value when the maximum efficiency value has been reached (in the steady-state period).

Fig. 11 is an enlargement of Fig. 10 to show the acceleration of achieving the maximum efficiency operating area (steady-state period). Moreover, Fig. 11 also shows the difference in the amplitude of oscillation of the efficiency value at steady-state conditions. 
Table 2. Loading scenario of the SS-CAES

\begin{tabular}{ccc}
\hline $\begin{array}{c}\text { Time Periods } \\
\text { (second) }\end{array}$ & $\begin{array}{c}\text { Resistive Load } \\
\text { (ohm) }\end{array}$ & $\begin{array}{c}\text { Output Power } \\
\text { (watt) }\end{array}$ \\
\hline \hline $0-20$ & 4.17 & 50 \\
$20-40$ & 1.67 & 20 \\
$40-60$ & 1.25 & 15 \\
$60-80$ & 2.25 & 27 \\
$80-100$ & 1.00 & 12 \\
$100-120$ & 1.50 & 18 \\
$120-140$ & 2.50 & 30 \\
$140-160$ & 2.00 & 24 \\
\hline
\end{tabular}

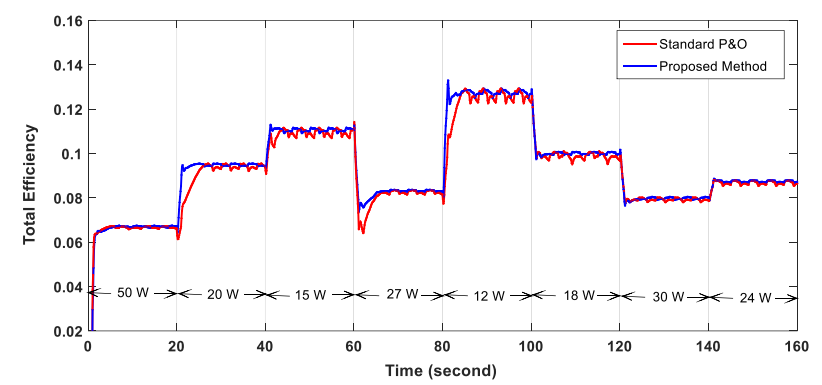

Figure. 10 Performance of proposed method



Figure. 11 Increase in search performance

Table 3. Average efficiency in each loading period

\begin{tabular}{|c|c|c|c|}
\hline \multirow{2}{*}{$\begin{array}{c}\text { Time } \\
\text { Periods } \\
\text { (second) }\end{array}$} & \multicolumn{2}{|c|}{ Average Efficiency (\%) } & \multirow{2}{*}{$\begin{array}{c}\text { Increasing } \\
\text { Efficiency } \\
(\%)\end{array}$} \\
\hline & $\begin{array}{c}\text { Standard } \\
\text { P\&O }\end{array}$ & $\begin{array}{c}\text { Proposed } \\
\text { Method }\end{array}$ & \\
\hline $0-20$ & 6.28 & 6.29 & 0.01 \\
\hline $20-40$ & 9.05 & 9.36 & 0.31 \\
\hline $40-60$ & 10.86 & 11.02 & 0.16 \\
\hline $60-80$ & 8.09 & 8.28 & 0.19 \\
\hline $80-100$ & 12.25 & 12.59 & 0.35 \\
\hline $100-120$ & 9.97 & 10.08 & 0.11 \\
\hline $120-140$ & 7.98 & 8.02 & 0.04 \\
\hline $140-160$ & 8.66 & 8.72 & 0.06 \\
\hline
\end{tabular}

As a result of accelerating the maximum efficiency point's attainment and decreasingoscillations in the steady-state area, there is also an increase in the average efficiency value in each loading period. In loading times from 20 seconds to 40 seconds, the standard $\mathrm{P} \& \mathrm{O}$ method

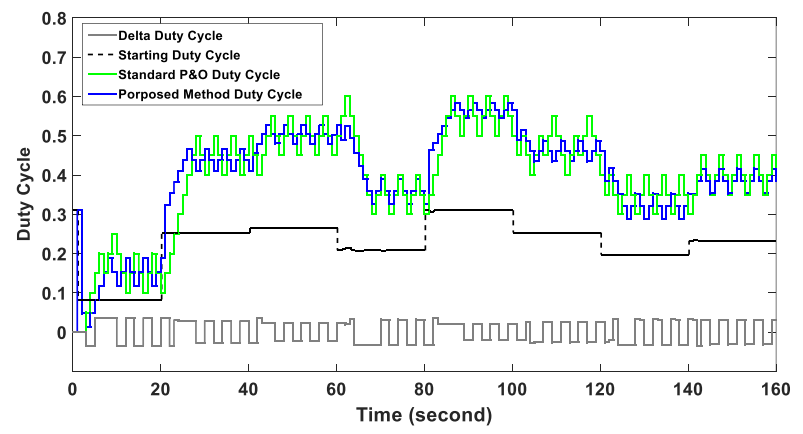

Figure. 12 Duty cycles



Figure. 13 Relation between $S D C, D D C$ and $D C$

achieves an average efficiency of about $9.05 \%$, while using the proposed method, the average efficiency is $9.36 \%$. It means an increase in efficiency due to the accelerated attainment of the maximum efficiency point and decreased oscillations in the steady-state period, about $0.31 \%$.

Table 3 shows the average efficiency value at each loading period and the increase in average efficiency with applying this proposed method.

\subsection{Duty cycle and delta duty cycle}

In both of these methods, DC is a decision from a review of several conditions. $\mathrm{DC}$ in the standard $\mathrm{P} \& \mathrm{O}$ changed by using fixed DDC, while in the proposed method, DC changed by using a variety of DDC, which is the result of the MIMO fuzzy algorithm decision by considering the amount of output power and efficiency values at that time, and the value SDC is also used to start the search period.

Fig. 12 shows the variation of all DC values in all loading periods, while Fig. 13 magnifies Fig. 12, in a certain period, to clarify more the relationship between DC, SDC, and DDC of the proposed method. Fig. 12 and Fig. 13 also show the variation in the DC values of the standard $\mathrm{P} \& \mathrm{O}$ for comparison.

In Fig. 12, and Fig. 13, DDC values can be positive and negative. DDC's algebraic value is the product of the algebraic sign of the delta efficiency and the delta speed generator at a given time.

The graph shows that the DDC of the proposed method in the steady-state area is smaller than the 




Figure. 14 Output voltage and speed

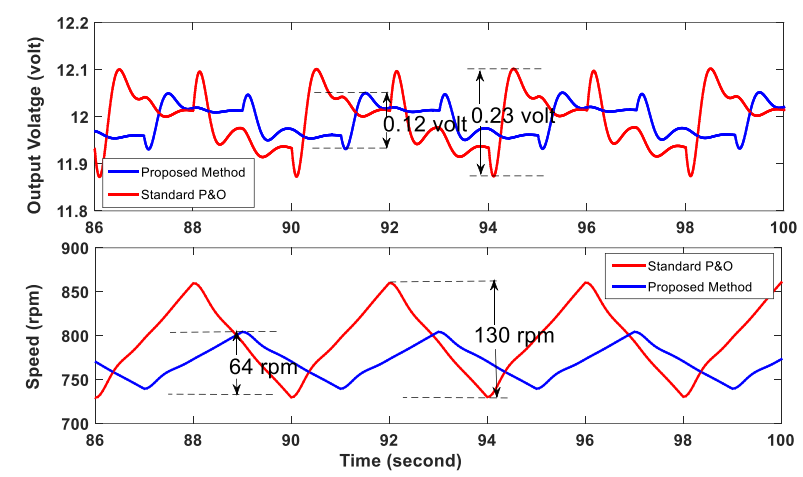

Figure. 15 Reducing voltage and speed oscillation

standard P\&O DDC, which causes a decrease in the oscillation value in that area.

\subsection{The effect of duty cycle to other system parameters}

As stated in Eq. (11) and Eq. (13), the generator output voltage $\left(V_{t}\right)$ is a quantity that is directly proportional to the generator speed $\left(\omega_{\mathrm{r}}\right)$, while the output voltage of the dc/dc converter $\left(V_{o}\right)$ depends on the DC value, as expressed in Eq. 14. However, DC changes due to tracking and oscillating activities in the steady-state area still result in a motorized valve response to maintain a constant voltage at a value of about 12 volts. Therefore, the faster the system reaches its maximum efficiency operating point, the smaller the oscillation generated in this steady-state area will minimize power consumption to drive the motorized valve.

Fig. 14 shows a graph of the output voltage and speed oscillation resulting from the search for the maximum efficiency of these two methods. With the magnification depicted in Fig. 15, we can see that the proposed method's voltage and speed oscillation are smaller than the standard $\mathrm{P} \& \mathrm{O}$ method.

The power to drive a motorized valve is not included in the efficiency calculation in modeling this system, but it is clear that to move a motorized valve requires power. The greater the opening or closing of the valve, and the more often it is done, the greater
Table 4. Average efficiency in each loading power

\begin{tabular}{cc|cc}
\hline $\begin{array}{c}\text { Output } \\
\text { Power } \\
\text { (watt) }\end{array}$ & $\begin{array}{c}\text { Avarage } \\
\text { Inlet } \\
\text { Pressure } \\
\text { (bar) }\end{array}$ & $\begin{array}{c}\text { Proposed } \\
\text { Method } \\
\text { Efficiency } \\
\text { (\%) }\end{array}$ & $\begin{array}{c}\text { Maximum } \\
\text { Air motor } \\
\text { Efficiency } \\
\text { (\%) }\end{array}$ \\
\hline 50 & 5.3 & 6.29 & 12.67 \\
20 & 3.2 & 9.36 & 15.74 \\
15 & 2.7 & 11.02 & 17.03 \\
27 & 3.7 & 8.28 & 14.78 \\
12 & 2.4 & 12.59 & 18.02 \\
18 & 3.0 & 10.08 & 16.19 \\
30 & 3.9 & 8.02 & 14.45 \\
24 & 3.4 & 8.72 & 15.33 \\
\hline
\end{tabular}

the power will require.

In addition to performance improvements by adding the Fuzzy MIMO algorithm to the standard $\mathrm{P} \& \mathrm{O}$ in this MEPT process, to clarify the novelty of this study, we compare the results of this study with the research publications by Kokaew et al. [25,27].

These two studies discuss the operation of standalone SS-CAES using the $\mathrm{P} \& \mathrm{O}$ algorithm. The fundamental differences between these two studies and our research are: (1) Both of these studies used a buck converter to regulate the operation of MPPT and MEPT on SS-CAES, while we used a boost converter. (2) Both of these previous studies did not specify the converter's output voltage, while we use 12 volts of voltage as an indicator of the adequacy of the power required by the load. (3) In these two studies, MPPT and MEPT process carried out regarding the pressure variations regulated using a pressure regulator, whereas, in our study, the output pressure on the motorized valve is a response to the result of setting the voltage at 12 volts and as a response to the MEPT process.

To compare the proposed method's results in this study with the previous two studies, we present Table 4. This table shows that for loading 50 watts, the maximum efficiency of the air motor is $12.67 \%$, which is similar to the maximum efficiency results in [25] when using the MEPT scenario with load 50 watts.

Furthermore, we carried out another comparison of results by comparing the pressure required to generate 30 watts of power between the proposed method and the result of [27]. Table 4 shows that to produce 30 watts of power using the proposed method requires an average air pressure at the inlet of the air motor of 3.9 bars and [27] also uses a similar pressure.

Also, comparing the efficiency graph for the MEPT scenario in [25] with the efficiency graph of the proposed method in Fig. 10 and Fig. 11, we can see an increase in performance using this proposed 
method. It appears that the proposed method takes less time to reach the maximum efficiency value compared to the previous method.

\section{Conclusion}

The P\&O method enriched with MIMO fuzzy algorithm to improve the MEPT process from the SSCAES model with the standard $\mathrm{P} \& \mathrm{O}$ algorithm has been implemented successfully. This proposed method results in an acceleration of the search for maximum efficiency operating points and a decrease in the efficiency value oscillation in its steady-state period.

In the proposed $\mathrm{P} \& \mathrm{O}$ method, MIMO Fuzzy functions to determine the starting duty cycle (SDC) value and delta duty cycle (DDC) of PWM signals of the boost converter placed at the generator output.

Testing the proposed method using a loading scenario and comparing it with the standard $\mathrm{P} \& \mathrm{O}$ method loaded with the same loading scenario increase the average efficiency value of $1.22 \%$.

In addition, increasing the oscillation value by selecting the appropriate DDC value reduces the amplitude of speed oscillation, which has implications for the power consumption used to drive the motorized valve. The decrease in the value of the oscillation speed in the steady-state area is about $50 \%$, which can be interpreted as power saving to move the motorized valve.

Compared with the MEPT method for similar systems in [25], this proposed method also shows better performance than the MEPT method used in previous studies in terms of accelerating maximum efficiency.

\section{Conflicts of Interest}

The authors declare no conflict of interest.

\section{Author Contributions}

Conceptualization, Ardyono Priyadi, Hajime MIYAUCHI, and Mauridhi Hery Purnomo; methodology, Andi Setiawan Mauridhi Hery Purnomo; software, Andi Setiawan; validation, Andi Setiawan; formal analysis, Andi Setiawan, Ardyono Priyadi, Hajime MIYAUCHI, and Mauridhi Hery Purnomo; writing — original draft preparation, Andi Setiawan; writing - review and editing, Andi Setiawan, Ardyono Priyadi, and Mauridhi Hery Purnomo; visualization, Andi Setiawan; supervision, Ardyono Priyadi, Hajime MIYAUCHI, and Mauridhi Hery Purnomo; project administration, Andi Setiawan.

\section{Acknowledgments}

This work is supported by Ministry of Education and Culture, Grant in Research for Doctoral Program, 2018. And the Matlab used in this work is supported by Institut Teknologi Sepuluh Nopember.

\section{References}

[1] B. Cleary, A. Duffy, A. O'Connor, M. Conlon, and V. Fthenakis, "Assessing the economic benefits of compressed air energy storage for mitigating wind curtailment", IEEE Trans. Sustain. Energy, Vol. 6, No. 3, pp. 1021-1028, 2015, doi: 10.1109/TSTE.2014.2376698.

[2] A. Arabkoohsar, L. Machado, M. FarzanehGord, and R. N. N. Koury, "Thermo-economic analysis and sizing of a PV plant equipped with a compressed air energy storage system", Renew. Energy, Vol. 83, pp. 491-509, 2015, doi: 10.1016/j.renene.2015.05.005.

[3] T. Basbous, R. Younes, A. Ilinca, and J. Perron, "Optimal management of compressed air energy storage in a hybrid wind-pneumatic-diesel system for remote area's power generation", Energy, Vol. 84, pp. 267-278, 2015, doi: 10.1016/j.energy.2015.02.114.

[4] X. Luo, J. Wang, M. Dooner, J. Clarke, and C. Krupke, "Overview of current development in compressed air energy storage technology", Energy Procedia, Vol. 62, pp. 603-611, 2014, doi: 10.1016/j.egypro.2014.12.423.

[5] H. Meng, M. Wang, O. Olumayegun, X. Luo, and $\mathrm{X}$. Liu, "Process design, operation and economic evaluation of compressed air energy storage (CAES) for wind power through modelling and simulation", Renew. Energy, Vol. 136, pp. 923-936, 2019, doi: 10.1016/j.renene.2019.01.043.

[6] A. Gafazi, A. Cheknane, I. Merzouk, and B. Seddik, "Control of A Three Levels AC / DC Converter With Virtual-Flux Direct Power Controlling Method for Grid-Connected Wind Power System Under Grid' S Fault', J. Eng. Sci. Technol., Vol. 13, No. 7, pp. 2236-2245, 2018.

[7] A. Castillo and D. F. Gayme, "Grid-scale energy storage applications in renewable energy integration: A survey", Energy Convers. Manag., Vol. 87, pp. 885-894, 2014, doi: 10.1016/j.enconman.2014.07.063.

[8] O. Phochai, W. Ongsakul, J. Mitra, and S. Member, "Voltage Control Strategies for GridConnected Solar PV Systems", In: Proc. of Int. Conf. Util. Exhib. 2014 Green Energy Sustain. Dev., No. March, pp. 19-21, 2014. 
[9] C. Veerasathian, W. Ongsakul, and J. Mitra, "Voltage stability assessment of DFIG wind turbine in different control modes", In: Proc. of Int. Conf. Util. Exhib. 2014 Green Energy Sustain. Dev., No. March, pp. 1-6, 2014.

[10] Widjonarko, R. Soenoko, S. Wahyudi, and E. Siswanto, "Comparison of intelligence control systems for voltage controlling on small scale compressed air energy storage", Energies, Vol. 12, No. 5, pp. 25-28, 2019, doi: 10.3390/en12050803.

[11] B. Castellani and F. Rossi, "Small-Scale Compressed Air Energy Storage Application for Renewable Energy Integration in a Listed Building", Energies, Vol. 11, 2018, doi: 10.3390/en11071921.

[12] G. Venkataramani, P. Parankusam, V. Ramalingam, and J. Wang, "A review on compressed air energy storage - A pathway for smart grid and polygeneration", Renew. Sustain. Energy Rev., Vol. 62, pp. 895-907, 2016, doi: 10.1016/j.rser.2016.05.002.

[13] H. Jin, P. Liu, and Z. Li, "Dynamic modeling and design of a hybrid compressed air energy storage and wind turbine system for wind power fluctuation reduction", Comput. Chem. Eng., pp. 59-65, 2019, doi: 10.1016/j.compchemeng. 2018.05.023.

[14] G. Grazzini and A. Milazzo, "Thermodynamic analysis of CAES/TES systems for renewable energy plants", Renew. Energy, Vol. 33, No. 9, pp. 1998-2006, 2008, doi: 10.1016/j.renene.2007.12.003.

[15] P. Zhao, Y. Dai, and J. Wang, "Design and thermodynamic analysis of a hybrid energy storage system based on A-CAES (adiabatic compressed air energy storage) and FESS (flywheel energy storage system) for wind power application", Energy, Vol. 70, pp. 674684, 2014, doi: 10.1016/j.energy.2014.04.055.

[16] M. Martinez, M. G. Molina, F. Frack, and P. E. Mercado, "Dynamic modeling, simulation and control of hybrid energy storage system based on compressed air and supercapacitors", IEEE Lat. Am. Trans., Vol. 11, No. 1, pp. 466-472, 2013, doi: 10.1109/TLA.2013.6502847.

[17] G. Kleiser and V. Rauth, "Dynamic Modelling of Compressed Air Energy Storage for SmallScale Industry Applications", Int. J. Energy Eng., Vol. 3, No. 3, pp. 127-137, 2013, doi: 10.5923/j.ijee.20130303.02.

[18] M. Martínez, M. G. Molina, and P. E. Mercado, "Dynamic performance of compressed air energy storage (CAES) plant for applications in power systems", In: Proc. of Transm. Distrib.
Conf. Expo. Lat. Am. (T\&D-LA), 2010 IEEE/PES, pp. 496-503, 2010, doi: 10.1109/TDC-LA.2010.5762928.

[19] E. Fertig and J. Apt, "Economics of compressed air energy storage to integrate wind power: A case study in ERCOT", Energy Policy, Vol. 39, No. 5, pp. 2330-2342, 2011, doi: 10.1016/j.enpol.2011.01.049.

[20] J. K. Kaldellis, D. Zafirakis, and K. Kavadias, "Techno-economic comparison of energy storage systems for island autonomous electrical networks", Renew. Sustain. Energy Rev., Vol. 13, No. 2, pp. 378-392, 2009, doi: 10.1016/j.rser.2007.11.002.

[21] Widjonarko, R. Soenoko, S. Wahyudi, and E. Siswanto, "Power curves prediction using empirical data regression on small scale compressed air energy storage", J. Mech. Eng. Sci., Vol. 13, No. 4, pp. 6144-6164, 2019, doi: 10.15282/jmes.13.4.2019.26.0482.

[22] M. Cheayb, S. Poncet, M. Marin-Gallego, and M. Tazerout, "Parametric Optimisation of a Trigenerative Small Scale Compressed Air Energy Storage System", Proc., Vol. 23, Vo. 1, p. 5, 2019, doi: 10.3390/proceedings2019023005.

[23] S. Lemofouet and a. Rufer, "A Hybrid Energy Storage System Based on Compressed Air and Supercapacitors With Maximum Efficiency Point Tracking (MEPT)", IEEE Trans. Ind. Electron., Vol. 53, No. 4, pp. 1105-1115, 2006, doi: 10.1109/TIE.2006.878323.

[24] Ł. Bartela, "A hybrid energy storage system using compressed air and hydrogen as the energy carrier", Energy, Vol. 196, 2020, doi: 10.1016/j.energy.2020.117088.

[25] V. Kokaew, M. Moshrefi-Torbati, and S. M. Sharkh, "Maximum efficiency or power tracking of stand-alone small scale compressed air energy storage system", Energy Procedia, Vol. 42, No. 0 , pp. 387-396, 2013, doi: 10.1016/j.egypro.2013.11.039.

[26] V. Kokaew and S. M. Sharkh, "A Hybrid Method for Maximum Power Tracking of a Small Scale CAES System", Int. Symp. Commun. Syst. Networks Digit. Sign, Vol. 9, pp. 61-66, 2014.

[27] V. Kokaew, S. M. Sharkh, and M. MoshrefiTorbati, "Maximum Power Point Tracking of a Small-Scale Compressed Air Energy Storage System", IEEE Trans. Ind. Electron., Vol. 63, No. 2, pp. 985-994, 2016, doi: 10.1109/ TIE.2015.2477344.

[28] N. Femia, G. Petrone, G. Spagnuolo, and M. Vitelli, "Optimization of perturb and observe 
maximum power point tracking method", IEEE Trans. Power Electron., Vol. 20, No. 4, pp. 963973, 2005, doi: 10.1109/TPEL.2005.850975.

[29] M. A. Elgendy, B. Zahawi, and D. J. Atkinson, "Evaluation of perturb and observe MPPT algorithm implementation techniques", In: Proc. of IET Conf. Publ., Vol. 2012, No. 592 CP, pp. 21-33, 2012, doi: 10.1049/cp.2012.0156.

[30] R. I. Putri, S. Wibowo, and M. Rifa'i, "Maximum power point tracking for photovoltaic using incremental conductance method", Energy Procedia, Vol. 68, pp. 22-30, 2015, doi: 10.1016/j.egypro.2015.03.228.

[31] K. L. Lian, J. H. Jhang, and I. S. Tian, "A maximum power point tracking method based on perturb-and-observe combined with particle swarm optimization", IEEE J. Photovoltaics, Vol. 4, No. 2, pp. 626-633, 2014, doi: 10.1109/JPHOTOV.2013.2297513.

[32] A. Copco, Atlas Copco Air Motor Features and Characteristics. Atlas Copco Corp., 2013.

[33] C. Us, "C23 Series Permanent Magnet DC Brush Motors Bene ts."

[34] A. K. Abdelsalam, A. M. Massoud, S. Ahmed, and P. N. Enjeti, "High-performance adaptive Perturb and observe MPPT technique for photovoltaic-based microgrids", IEEE Trans. Power Electron., Vol. 26, No. 4, pp. 1010-1021, 2011, doi: 10.1109/TPEL.2011.2106221.

[35] L. Piegari and R. Rizzo, "Adaptive perturb and observe algorithm for photovoltaic maximum power point tracking", IET Renew. Power Gener., Vol. 4, No. 4, pp. 317-328, 2010, doi: 10.1049/iet-rpg.2009.0006.

[36] T. Dogruer and N. Tan, "Design of PI Controller using Optimization Method in Fractional Order Control Systems", IFAC-PapersOnLine, Vol. 51, No. 4, pp. 841-846, 2018, doi: 10.1016/j.ifacol.2018.06.124.

[37] F. Verbelen, M. Haemers, J. De Viaene, S. Derammelaere, K. Stockman, and P. Sergeant, "Adaptive PI Controller for Slip controlled Belt Continuously Variable Transmission", IFACPapersOnLine, Vol. 51, No. 4, pp. 101-106, 2018, doi: 10.1016/j.ifacol.2018.06.045.

[38] K. H. Estévez-Sánchez, A. Sampieri-Croda, M. A. García-Alvarado, and I. I. Ruiz-López, "Design of multiloop PI controllers based on quadratic optimal approach", ISA Trans., Vol. 70, pp. 338-347, 2017, doi: 10.1016/j.isatra.2017.07.011.

[39] A. E. Geweda, M. A. El-Gohary, A. M. ElNabawy, and T. Awad, "Improvement of vehicle ride comfort using genetic algorithm optimization and PI controller", Alexandria Eng.
J., Vol. 56, No. 4, pp. 405-414, 2017, doi: 10.1016/j.aej.2017.05.014.

[40] C. R. Edgar and B. E. Postlethwaite, "MIMO fuzzy internal model control", Automatica, Vol. 36, No. 6, pp. 867-877, Jun. 2000, doi: 10.1016/S0005-1098(99)00213-7.

[41] S. Askari, "A novel and fast MIMO fuzzy inference system based on a class of fuzzy clustering algorithms with interpretability and complexity analysis," Expert Syst. Appl., Vol. 84, pp. 301-322, 2017, doi: 10.1016/j.eswa.2017.04.045.

[42] J. Soto, O. Castillo, P. Melin, and W. Pedrycz, "A New Approach to Multiple Time Series Prediction Using MIMO Fuzzy Aggregation Models with Modular Neural Networks", Int. J. Fuzzy Syst., Vol. 21, No. 5, pp. 1629-1648, 2019, doi: 10.1007/s40815-019-00642-w.

[43] Z. Zhou, B. Zhang, and D. Mao, "MIMO Fuzzy Sliding Mode Control for Three-Axis Inertially Stabilized Platform", Sensors, Vol. 19, No. 7, p. 1658, 2019, doi: 10.3390/s19071658. 